\title{
The Study of Bray-Liebhafsky Reaction over a Wide Range of Temperatures. I. Experimental Contributions
}

\author{
R. VÎLCU ${ }^{\mathrm{a}, *}$, T. DANCIU ${ }^{\mathrm{b}}$ and D. BALA ${ }^{\mathrm{a}}$ \\ ${ }^{a}$ Physical Chemistry Department, University of Bucharest, 13, Carol I Boulevard, 70346 Bucharest, Romania; \\ ' Chemical Engineering Department, University "Politehnica" of Bucharest, 1, Gh. Polizu Street, 78126 Bucharest, Romania
}

(Received 12 February 1998)

\begin{abstract}
Some experiments with a classical Bray-Liebhafsky system over a wide range of (assuming constant) temperatures were performed. The observed behavior shows (at least) one critical point. A qualitative interpretation is proposed.
\end{abstract}

Keywords: Chemical oscillations, Chemical instabilities, Chemical clocks, Chemical chaos, Chemical fluctuations

The Bray-Liebhafsky (shortly BL) reaction consists (from an overall point of view) of the oscillating decomposition of hydrogen peroxide (with evolving oxygen) catalyzed by potassium iodate from an acidic (sulfuric, perchloric) aqueous solution. It was briefly reported, first by Auger in 1911 and Bray in 1921, later by Liebhafsky in 1931. The production of oxygen was recorded being pulsed and oscillations in composition were observed from optical measurements. These oscillations have shown a strong dependence of the initial compositions of all compounds and, like other chemical oscillations (discovered much later), exhibit this exotic behavior over a tight range of these concentrations.

These earlier studies were poorly described while the entire system's behavior seemed to be impossible at the time. Some valuable proposals to explain the phenomena were made. A redox which alternates the reduction of iodate to iodine with oxidation of iodine to iodate and the presence of iodic acid given by iodate and sulfuric acid was considered. Meanwhile, a change of mind took place: because the reproductions of the experiments are rather difficult, various types of heterogeneities were assumed to cause the oscillations, i.e., the oscillations are not chemical ones. The heterogeneities most often invoked were dust particles (by Rice and Reiff in 1927) and oxygen bubbles (by Peard and Cullis in 1951).

As a definition, chemical oscillations (or chemical "clocks") are the systems in which chemical driver oscillations appear (in some concentrations) in spite of maintaining all physical parameters

* Corresponding author. 
(pressure, temperature, flow rate) constant. Purely chemical oscillations (without transport contributions) are considered to be only the liquid homogeneous systems (solutions) and, perhaps, some gaseous reactions with solid catalysts (for more details, see Cooke, 1977).

A major contribution in the study of $\mathrm{BL}$ reaction was given by the paper of Degn (1967). His works have resuscitated the interest for chemical oscillations in a more favorable context: the BelousovZhabotinskii reaction was reported previously. Also, Prigogine (1961) had published his irreversible thermodynamics, which allows chemical oscillations to exist, being a confirmation of the second principle (in a local form) because of the nonlinearity of the kinetic expressions.

The experiments published by Degn were performed (and described) rigorously. His interpretation of the reaction had some positive aspects, such as the presence of many intermediates containing iodine, but fails in any reproduction of the recorded observations. However, his model was a starting point for the famous Brusselator, proposed a year later (1968) to explain the BL reaction (see Part II of this work).

The principle of Degn's measurements was quite simple: all reactants but hydrogen peroxide were mixed up in fixed proportions to form a so-called "standard solution". The reaction with hydrogen peroxide took place (with stirring, at $65^{\circ} \mathrm{C}$ ) directly in a spectrophotometer's cell. The concentration of dissolved iodine was measured versus time, by absorption of light at $460 \mathrm{~nm}$ precisely (where a maximum of absorption was found).

Some major experimental contributions of Degn should be mentioned: in a closed system, not selfsustained but relaxation oscillations occur, the limits of oscillating domain according to sulfuric acid concentration were found. Also, some variants of the system (obtained by changing the acid or adding various substances, such as transition metal ions, alkaline halides or organic unsaturated compounds) were tested. He proposed a chain mechanism assuming free radicals as intermediates, based on the influence of the unsaturated com- pounds (like acrylamide) and halides (chlorides and bromides).

Other major experimental studies of BL reaction could be easily divided in three main groups. First, it stands the work of Liebhafsky and Wu (1974), Liebhafsky et al. $(1978 ; 1981)$ and Liebhafsky with different coworkers, like Matsuzaki et al. (1972) or Furuichi (1973; 1975). Another group consists of the papers of Noyes with different coworkers, like Sharma (1975; 1976), Odutola et al. (1982) or Treindl (1993). The third group contains the reports of Schmitz and Rooze (1979), Schmitz $(1984 ; 1987)$ coupled with those of Anic et al. (1985a,b; 1987; 1989; 1991), Anic and Kolar-Anic (1986a,b; 1987; 1988), Anic and Mitic (1988), first of all independent, later connected (Kolar-Anic et al., 1990a,b; 1994; Kolar-Anic and Schmitz, 1992).

Each group used specific experimental techniques and proposed specific models, which could be summarized as follows: Liebhafsky conducted his latest experiments in the same manner like the earlier ones (almost 40 years ago!). He used a periodical chemical analysis to measure the concentrations and worked mostly at only two temperatures: $25^{\circ} \mathrm{C}$ and $50^{\circ} \mathrm{C}$. Also, he tried to isolate different parts (branches) of the BL system in order to establish the mechanism, assuming an ionic (redox) one. Matsuzaki et al. (1972) have studied the BL system without iodate while Furuichi and Liebhafsky $(1973$; 1975) investigated the socalled Dushman system (BL without peroxide). Liebhafsky proposed several kinetic laws, most of them at low temperatures, where the reaction exhibits an ignition (non-oscillating) period.

The second group has done the most complete experiment, i.e., they measured (continuously) the concentrations of iodine (spectrophotometric), iodide (potentiometric) and oxygen evolved (volumetric). The experiment was conducted always at $50^{\circ} \mathrm{C}$; in their works, Sharma and Noyes (1975; 1976) have presented the results for iodide in the pI form. Assuming a much complex mechanism, various models were proposed, including many radicals, ions and the physical desorption of oxygen. Also, experiments which search for 
possible physical influences, such as stirring, illuminating or oxygen absorption, were performed.

The third group of papers, as mentioned already, is a combined one. It contains the work of Schmitz and Rooze (1979), Schmitz (1984; 1987), in which a synchronized experiment is described (spectroscopic for iodine and potentiometric for iodide, respectively) at $60^{\circ} \mathrm{C}$. Also, a purely ionic model, known as Braylator and containing a hypothetical intermediate, $\mathrm{I}_{2} \mathrm{O}$, is introduced. On the other hand, the same group contains the papers published by Anic et al. (1985a,b; 1987; 1989; 1991), Anic and Kolar-Anic (1986a,b; 1987; 1988), Anic and Mitic (1988), Kolar-Anic et al. (1990a,b; 1994), KolarAnic and Schmitz (1992), where the experiment was done mostly at $62^{\circ} \mathrm{C}$ and the measurement was potentiometric only. The authors from Serbia were the first who used sulfuric acid (like Degn) while all others above used perchloric acid instead. They found a so-called "second ignition period" at higher temperatures and performed a quenching analysis (restarting the oscillator by dilution). Because they adopted and developed the Braylator, one could consider theirs researches connected with those of Schmitz.

\section{EXPERIMENTAL REPORT}

We wish to present in this paper a part of our experiments with BL reaction. Although this reaction is reasonably well known from the beginning of the century, new experimental approaches could be made. The temperature was found to be a (somehow) neglected parameter by most of the authors: almost all reports have mentioned a constant temperature, its influence being poorly investigated and with no major results. Only few papers have shown an interest for the influence of the temperature. An example is Anic et al. (1989), where only three temperatures (relatively close) were tried. From other sources (Cooke, 1977), it seems that such experiments had been done before: Peard and Cullis in 1952 and Liebhafsky and coworkers in 1970. Nobody tried a temperature above $77^{\circ} \mathrm{C}$. To complete the studies of BL reaction, our experiments were performed over a wider range of temperatures. We tried to show the influence (if any) of this parameter over the oscillating domain and, furthermore, of the characteristics of these oscillations.

The experimental device was realized quite similar to Degn's, with the sacrifice of the stirring in exchange of using a performance thermostat (see Fig. 1 for details). The BL system was made, once again, like Degn's: a "standard solution", containing water, sulfuric acid and potassium iodate in preset proportions $\left(0.3 \mathrm{M} \mathrm{H}_{2} \mathrm{SO}_{4}\right.$ and $\left.0.046 \mathrm{M} \mathrm{KIO}_{3}\right)$. It was poured into the analysis cell of the spectrophotometer (made of quartz, having a volume of $3 \mathrm{ml}$ and an optical path of $10 \mathrm{~mm}$ ) and heated at a pre-set temperature (for example, $80^{\circ} \mathrm{C}$ ). The suitable quantity of oxygenated water $(80 \mu \mathrm{l}$ of $30 \%$ perhydrol) was added using a micro-syringe. Degn has considered a $9.8 \mathrm{M}$ concentration for $30 \%$ (mass percents) perhydrol, but according to the density at $20^{\circ} \mathrm{C}$ found in literature (Nenitescu, 1979) this value was taken (more precisely) $9.75 \mathrm{M}$. A chemical analysis (with potassium permanganate) was performed, giving almost the same value. Assuming a concentration of $9.75 \mathrm{M}$ for the perhydrol, the above quantity yields a $0.26 \mathrm{M} \mathrm{H}_{2} \mathrm{O}_{2}$ solution in the cell. Also, since the perhydrol is pumped quickly into the cell, a satisfactory initial mixing is assured (in our opinion). This technique was used previously (see for example, the work of Liebhafsky et al., 1974; 1978; 1981). The lack of any mechanical stirring after the initial moment was assumed to be negligible, according to Degn's considerations. This point is debatable, while other authors found a strong influence of stirring over the BL reaction. Liebhafsky et al. (1981) and Treindl and Noyes (1993) reported this fact, but the first mention was published in 1951 (Peard and Cullis).

The monochromatic beam of the spectrophotometer was set at $460 \mathrm{~nm}$ (see Degn, 1967). Slightly different values were tried during the time: $440 \mathrm{~nm}$ (Treindl and Noyes, 1993), $465 \mathrm{~nm}$ (Sharma and Noyes, 1976 and Schmitz, 1987), $470 \mathrm{~nm}$ (Furrow, 


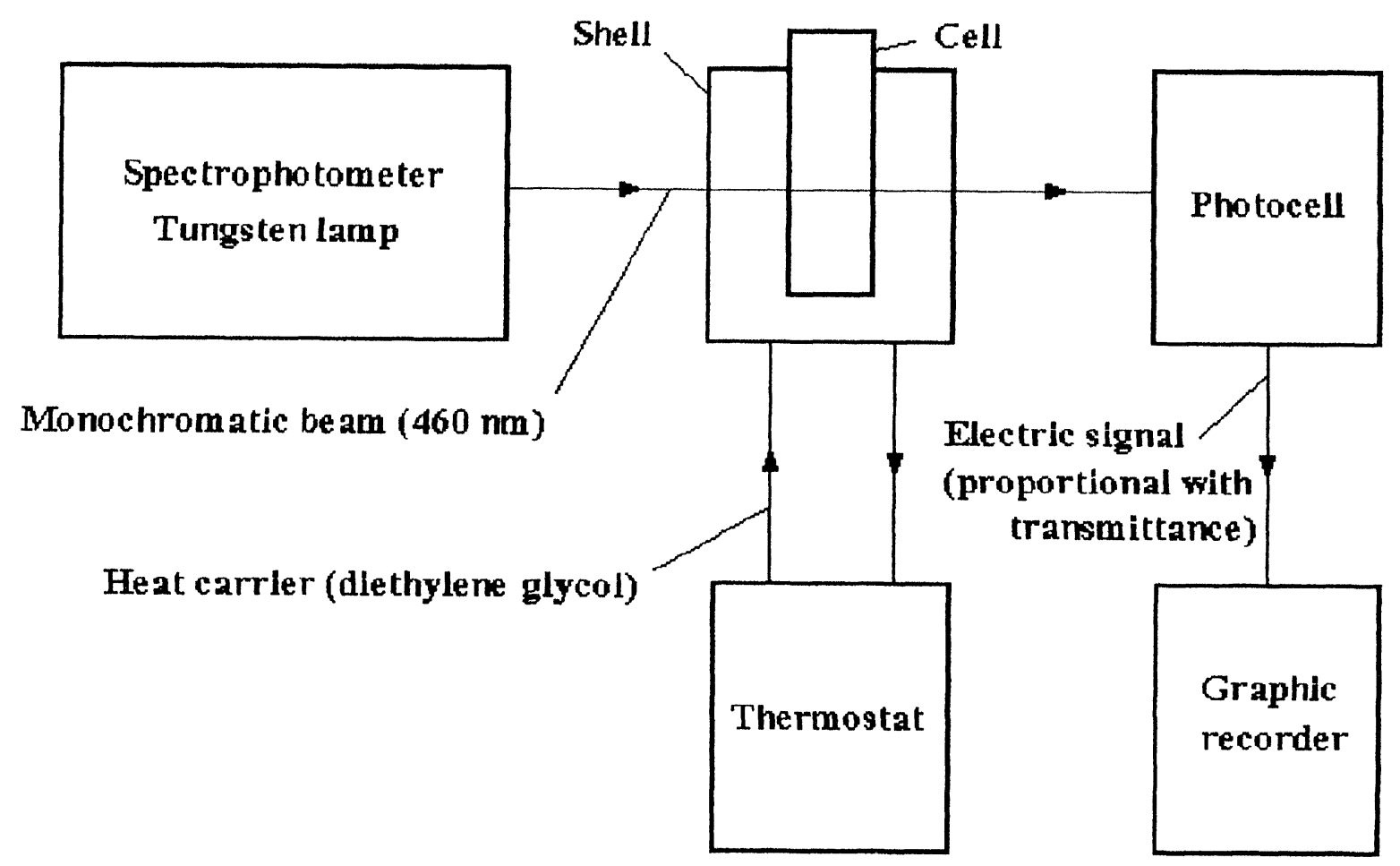

FIGURE 1 The connections diagram of the experimental device.

1985) or $525 \mathrm{~nm}$ (Odutola et al., 1982). While a relatively large quantity of standard solution is well thermostated at the fixed temperature, adding a small quantity of perhydrol at room temperature was assumed to not alter significantly the pre-set temperature. The recorded oscillograms which represent the concentration of dissolved iodine versus time exhibit a complex form, like in Fig. 2.

It is obvious that the scale for concentration is not linear, according to the required transformation from transmittance (the ordinate is linear with respect to this parameter). In our sources (Niac et al., 1984), the molar extinction coefficient which corresponds to a saturated iodine solution was $950 \mathrm{l} / \mathrm{mole} \cdot \mathrm{cm}$, not so far from other values utilized in literature $(7401 /$ mole. $\mathrm{cm}$ in Sharma and Noyes, 1976; 596.1 1/mole.cm in Treindl and Noyes, 1993; or $715 \mathrm{l} / \mathrm{mole} \cdot \mathrm{cm}$ in Schmitz, 1987). Anyway, this value can induce only a systematic error. On the other hand, the saturation of the BL system (at $50^{\circ} \mathrm{C}$ ) with respect to iodine is given by Liebhafsky

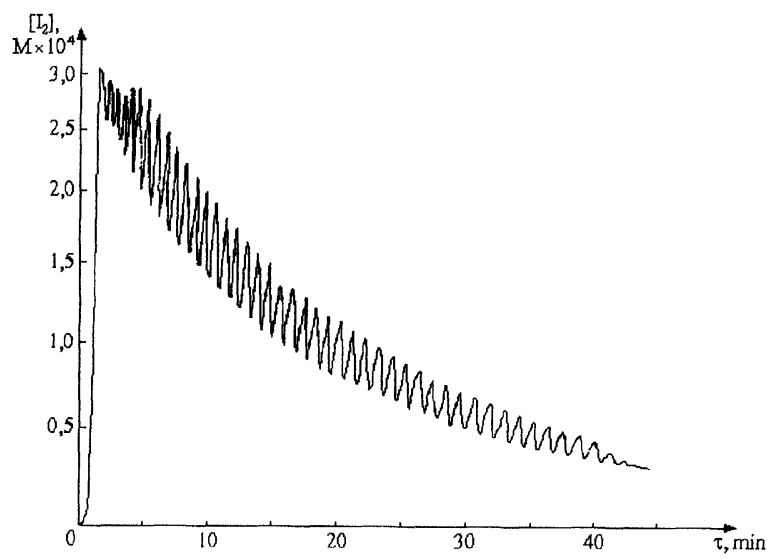

FIGURE 2 Time evolution of iodine concentration.

$\left(3.08 \times 10^{-3} \mathrm{M}\right)$ while Noyes found a "stationary state" at $10^{-3} \mathrm{M}$ (but with different initial concentrations of $\mathrm{KIO}_{3}$ and $\mathrm{H}^{+}$). We were ready to accept for this parameter a bigger value $\left(5 \times 10^{-3} \mathrm{M}\right)$ because of the larger temperature, but even the value of Noyes was never reached. 
In conclusion, our data are easy to reconcile with related values of dissolved iodine published in literature by taking into account that a perfect agreement is difficult in these cases (i.e., with so many degrees of freedom: wavelength, temperature, initial compositions).

From the moment of adding the hydrogen peroxide (considered to be the starting point of the reaction), the concentration of iodine increases very quickly, reaches a first maximum (sometimes more or less distinctive) and begins an oscillatory regime of relaxation (sometimes after a short period of ignition). On the other hand, the first portion of this regime is quasi-chaotic (one could say a "formation" or a "synchronization" regime). Some fluctuations are inherent during such a long time (from Fig. 2 it is obvious that some oscillations are not perfect).

All the procedure was repeated for different temperatures, keeping all other parameters (i.e., initial concentrations) constant. A selected set from our data is presented in Table I, giving some characteristics for the oscillating evolution obtained for various temperatures.

In addition, it should be mentioned that odd values of the temperatures above are due to the correction made for heat losses. In order to find the true temperature in the cell, a platinum thermistor in a Wheatstone bridge was used. An overall examination of Table I shows that, when temperature increases, the occurrence of the first maximum

TABLE I Oscillations of iodine concentration over a wide range of temperatures

\begin{tabular}{|c|c|c|c|c|c|c|}
\hline \multirow[t]{2}{*}{ Temperature $\left({ }^{\circ} \mathrm{C}\right)$} & \multicolumn{2}{|c|}{ First maximum } & \multicolumn{3}{|c|}{ Oscillatory domain } & \multirow[t]{2}{*}{ Observations } \\
\hline & $\begin{array}{l}\text { Time* } \\
(\min )\end{array}$ & $\begin{array}{c}\text { Value } \\
\left(\mathrm{M} \times 10^{4}\right)\end{array}$ & $\begin{array}{c}\text { Time** } \\
(\mathrm{min})\end{array}$ & $\begin{array}{l}\text { Duration } \\
\text { (min) }\end{array}$ & No.*** & \\
\hline 62.4 & 4.16 & 1.238 & 23.83 & 121 & 68 & $\begin{array}{l}\text { A non-oscillatory second induction } \\
\text { period }\end{array}$ \\
\hline 63.4 & 4.33 & 1.238 & 21.5 & 107 & 63 & $"$ \\
\hline 64.4 & 3.66 & 1.403 & 21.33 & 124 & 66 & $\begin{array}{l}\text { Non-countable fluctuations in the second } \\
\text { induction period }\end{array}$ \\
\hline 64.9 & 4.5 & 1.593 & 10.33 & 153 & 82 & $"$ \\
\hline 65.5 & 3.5 & 1.525 & 14.33 & 126 & 72 & $"$ \\
\hline 66.9 & 3.5 & 1.672 & 13.33 & 112 & 76 & $\begin{array}{l}\text { Synchronization with irregular } \\
\text { oscillations included in Col. } 6\end{array}$ \\
\hline 67.8 & 3.33 & 1.712 & 9.66 & 106 & 76 & $"$ \\
\hline 68.8 & 3.33 & 1.936 & 9 & 99 & 72 & $"$ \\
\hline 70.7 & 2.66 & 2.043 & 6.33 & 94 & 69 & ” \\
\hline 71.7 & 2.83 & 2.217 & 7 & 86 & 65 & $"$ \\
\hline 72.6 & 2.5 & 2.4 & 7.33 & 80 & 60 & $"$ \\
\hline 73.6 & 3 & 2.446 & 9.66 & 79 & 57 & $"$ \\
\hline 74.6 & 2.66 & 2.493 & 9 & 73 & 55 & $"$ \\
\hline 75.6 & 2.16 & 2.4 & 6.5 & 66 & 57 & Second maximum exceeds the first one \\
\hline 80.3 & 1.66 & 3.02 & 3.83 & 43 & 45 & $"$ \\
\hline 81.4 & 2.16 & 3.294 & 3.16 & 37 & 39 & $"$ \\
\hline 82.3 & 2 & 3.466 & 2.66 & 38 & 35 & ” \\
\hline 83.3 & 1.66 & 3.238 & 3.33 & 36 & 34 & $"$ \\
\hline 84.2 & 1.5 & 4.06 & 2.66 & 34 & 32 & " \\
\hline 85.2 & 1.16 & 3.707 & 1.66 & 23 & 33 & $"$ \\
\hline 86.2 & 1.33 & 4.628 & 0 & 25 & 29 & $\begin{array}{l}\text { Synchronization disappears } \\
\text { (the first maximum is masked) }\end{array}$ \\
\hline 87.1 & 1.66 & 5.105 & 0 & 26 & 27 & $"$ \\
\hline 88.1 & 1.66 & 5.32 & 0 & 24 & 25 & $"$ \\
\hline 89.0 & 1 & 5.064 & 0 & 19 & 27 & $"$ \\
\hline 90.0 & 1 & 4.743 & 0 & 18 & 25 & $"$ \\
\hline
\end{tabular}

*Since the starting point of the reaction; ${ }^{* *}$ since the first maximum occurs; ${ }^{* * *}$ oscillations which could be easily counted, i.e., including (or not) the synchronization period (see last column for more details). 
of iodine concentration becomes faster, its amplitude and the amplitudes of individual oscillations grow while the number of oscillations, the damping time and the period of individual oscillations ceases.

\section{QUALITATIVE INTERPRETATION OF RESULTS}

After a cross examination of our results and other experimental reports, we consider a new scenario for $\mathrm{BL}$ reaction. It will be described with respect to the temperature, according to our method and consists of few different behaviors which one could expect when watching a BL system. First of all, an overview of many experiments pictured that dissolved iodine concentration follows always an ordinary evolution of an intermediate species. This behavior consists of a null starting point (the initial concentration being zero), a growth to maximum and an asymptotic relaxation to a stationary value (zero). This maximum appears faster and is sharper when temperature increases, its profile being sensitive at initial concentrations too. Although it is called elsewhere "a single oscillation" or sometimes it is not very distinct from the oscillations, in our opinion the behavior is not connected with the oscillatory regime.

The oscillations come from background and are superposed (but not in resonance) over the intermediate profile of iodine. This means that dissolved iodine is not the key intermediate for oscillations; it only reflects the oscillations induced by other species. The occurrence of oscillations strongly depends on initial concentrations' ratio. On the other hand, it seems that the temperature has a major influence over how these oscillations look like and some critical points could be seen in Table I.

At lower temperatures (and suitable concentrations, in order for an oscillatory regime to exist) an ignition (induction) period was found. This means that oscillations start only after relatively long time from the first maximum of iodine concentrations. In some sources, where the first maximum is called "a single oscillation", this period of ignition is assumed to be the second one. Its duration was found to be inversely proportional with tempera- ture and perhydrol initial concentration. This domain is called elsewhere "smooth catalysis" and its major characteristic consists of damped oscillations at both ends of the oscillatory regime. In this case, a reinitiation of oscillations by dilution is impossible, because of the total consumption of perhydrol (Anic et al., 1991).

As the temperature increases, the oscillations are bigger in amplitude but smaller in period and their number ceases, as the total time of the oscillatory domain. At a critical point (for above concentrations, at $64.4^{\circ} \mathrm{C}$, see Table I), the induction period begins to oscillate also. For a tight domain of temperature, one could see only small fluctuations (which are not countable). After this, the second ignition period becomes a "synchronization" period, with pretty irregular oscillations well developed, although they are a little bit smaller than oscillations from the mean part of oscillatory regime.

First interpreted like a consequence of lack of stirring, this behavior remains about the same for a relatively wide range of temperature. One could say that at least a critical temperature exists in the range of $60-65^{\circ} \mathrm{C}$, where the oscillating behavior becomes spontaneous. It should be mentioned that all other tendencies remain the same; amplitudes grow while periods cease, and so on. If only one critical temperature is considered, there has to be an activation (a change of some mechanism).

A second (or third) critical temperature could exist above $85^{\circ} \mathrm{C}$, where any "synchronization" disappears. An upper limit for the spontaneous oscillating regime of $\mathrm{BL}$ reaction could not be found (above $90^{\circ} \mathrm{C}$, the evaporation of the aqueous solution induces too many fluctuations). Reinitiation of oscillations by dilution in this domain (Anic et al., 1991) confirms above considerations and pictures that the oscillatory regime is only a region of $\mathrm{BL}$ reaction.

In conclusion, the complete mechanism of this reaction is perhaps much complicated as any one could think. The possibility of two different behaviors with respect to temperature should be considered at some concentration. That major change in BL mechanism by some activation must 
imply dissolved iodine, but also the intermediate from background, those which oscillations are due too. In Part II of this work, the Dushman reaction is assumed to be the process while the iodide is considered to be the intermediate.

\section{References}

Anic, S., Mitic, D. and Kolar-Anic, L. (1985a). The BrayLiebhafsky reaction. I. Controlled development of oscillations. J. Serb. Chem. Soc. 50, 53-59.

Anic, S., Mitic, D., Veselinovic, D. and Kolar-Anic, L. (1985b). The Bray-Liebhafsky reaction. II. Potentiometric and $\mathrm{pH}-$ metric tracing. J. Serb. Chem. Soc. 50, 529-533.

Anic, S. and Kolar-Anic, L. (1986a). Some new details in the kinetic considerations of the oscillatory decomposition of hydrogen peroxide. Ber. Bunsenges. Phys. Chem. 90, 539-542.

Anic, S. and Kolar-Anic, L. (1986b). The oscillatory decomposition of $\mathrm{H}_{2} \mathrm{O}_{2}$ monitored by the potentiometric method with $\mathrm{Pt}$ and $\mathrm{Ag}^{+} / \mathrm{S}^{2-}$ indicator electrode. Ber. Bunsenges. Phys. Chem. 90, 1084-1086.

Anic, S. and Kolar-Anic, L. (1987). The influence of potassium iodate on hydrogen peroxide decomposition in BrayLiebhafsky reaction. Ber. Bunsenges. Phys. Chem. 91, 10101013.

Anic, S., Mitic, D. and Curcija, M. (1987). The Bray-Liebhafsky reaction. III. Oscillatory decomposition of $\mathrm{H}_{2} \mathrm{O}_{2}$ in the presence of comparatively high acidity. J. Serb. Chem. Soc. $\mathbf{5 2}, 575-579$.

Anic, S. and Mitic, D. (1988). The Bray-Liebhafsky reaction. IV. New results in the studies of hydrogen peroxide oscillatory decomposition at high acidity. J. Serb. Chem. Soc. 53, 371-376.

Anic, S. and Kolar-Anic, L. (1988). Kinetic aspects of the BrayLiebhafsky oscillatory reaction. J. Chem. Soc., Faraday Trans. 84, 3413-3421.

Anic, S., Stanisavljev, D., Krnajski Belovljev, G. and KolarAnic, L. (1989). Examination of the temperature variations on the Bray-Liebhafsky oscillatory reaction. Ber. Bunsenges. Phys. Chem. 93, 488-491.

Anic, S., Kolar-Anic, L., Stanisavljev, D., Begovic, N. and Mitic, D. (1991). Dilution reinitiated oscillations in the BrayLiebhafsky system. React. Kinet. Catal. Lett. 43, 155-162.

Cooke, D.O. (1977). Homogeneous liquid phase inorganic oscillatory reactions: Chemical aspects. Progr. Reaction Kinetics 8, 185-229.

Degn, H. (1967). Evidence of a branched chain reaction in the oscillating reaction of hydrogen peroxide, iodine and iodate. Acta Chem. Scand. 21, 1057-1066.

Furrow, S.D. (1985). Chemical oscillations based on iodate ion and hydrogen peroxide. In Oscillations and Travelling Waves in Chemical Systems (R.J. Field and M. Burger, Eds.). J. Wiley, New York, p. 171.

Furuichi, R. and Liebhafsky, H.A. (1973). Radioactive iodine exchange and the Dushman reaction. Bull. Chem. Soc. Japan. 46, 2008-2010.

Furuichi, R. and Liebhafsky, H.A. (1975). Rate of the Dushman reaction in iodic acid at low iodide concentration. Complexity of iodic acid. Bull. Chem. Soc. Japan 48, 745-750.

Kolar-Anic, L.Z., Misljenovic, D.M., Stanisavljev, D.R. and Anic, S.R. (1990a). Applicability of Schimtz's model to dilution-reinitiated oscillations in the Bray-Liebhafsky reaction. J. Phys. Chem. 94, 8144-8146.

Kolar-Anic, L., Stanisavljev, D., Krnajski Belovjev, G. Peeters, P. and Anic, S. (1990b). The first maximum of the iodide concentration in the Bray-Liebhafsky reaction. Computers Chem. 14, 345-347.

Kolar-Anic, L. and Schmitz, G. (1992). Mechanism of the BrayLiebhafsky reaction: Effect of the oxidation of iodous acid by hydrogen peroxide. J. Chem. Soc., Faraday Trans. 88, 2343-2349.

Kolar-Anic, L., Misljenovic, D. and Anic, S. (1994). Modelling of Bray-Liebhafsky process. The theoretical analysis of the role of the reaction $\mathrm{IO}_{3}^{-}+\mathrm{I}^{-}+2 \cdot \mathrm{H}^{+} \rightleftharpoons \mathrm{HIO}+\mathrm{HIO}_{2}$. In Dynamics Days, 15th Annual Informal Workshop, Budapest, pp. 1-9.

Liebhafsky, H.A. and Wu, L.S. (1974). Reactions involving hydrogen peroxide, iodine and iodate ion. V. Introduction to the oscillatory decomposition of hydrogen peroxide. J. Am. Chem. Soc. 96, 7180-7187.

Liebhafsky, H.A., McGavock, W.C., Reyes, R.J., Roe, G.M. and Wu, L.S. (1978). Reactions involving hydrogen peroxide, iodine and iodate ion. 6. Oxidation of iodine by hydrogen peroxide at $50^{\circ}$ C. J. Am. Chem. Soc. 100, 87-91.

Liebhafsky, H.A., Furuichi, R. and Roe, G.M. (1981). Reactions involving hydrogen peroxide, iodine and iodate ion. 7. The smooth catalytic decomposition of hydrogen peroxide, mainly at $50^{\circ} \mathrm{C} \mathrm{J.} \mathrm{Am.} \mathrm{Chem.} \mathrm{Soc.} \mathrm{103,} \mathrm{51-56.}$

Matsuzaki, I., Simic, R. and Liebhafsky, H.A. (1972). The mechanism of decomposition of hydrogen peroxide by iodine in acid solutions. The rates of associated reactions. Bull. Chem. Soc. Japan 45, 3367-3371.

Nenitescu, C.D. (1979). General Chemistry (in Romanian). Didactic and Pedagogic Publishing House, Bucharest, p. 654.

Niac, G., Voiculescu, V., Bâldea, I. and Preda, M. (1984). Formula, Tables, Problems of Physical Chemistry (in Romanian). Dacia, Cluj-Napoca, p. 258.

Odutola, J.A., Bohlander, C.A. and Noyes, R.M. (1982). Chemical oscillations and instabilities. 46. Iodide ion measurements on the oscillatory iodate-peroxide system. J. Phys. Chem. 86, 818-824.

Prigogine, I. (1961). Introduction to Thermodynamics of Irreversible Processes. Second edition, John Wiley, New York.

Schmitz, G. and Rooze, H. (1979). In Synergetics, Far from Equilibrium (Springer Series in Synergetics 3, A. Pacault and C. Vidal, Eds.), Springer-Verlag, Berlin, Heidelberg, New York, Tokyo, pp. 51-56.

Schmitz, G. (1984). In Non-Equilibrium Dynamics in Chemical Systems (Springer Series in Synergetics 27, C. Vidal and A. Pacault, Eds.), Springer-Verlag, Berlin, Heidelberg, New York, Tokyo, p. 237.

Schmitz, G. (1987). Cinétique de la réaction de Bray. J. Chim. Phys. 84, 957-965.

Sharma, K.R. and Noyes, R.M. (1975). Oscillations in chemical systems. VII. Effects of light and of oxygen on the BrayLiebhafsky reaction. J. Am. Chem. Soc. 97, 202-204.

Sharma, K.R. and Noyes, R.M. (1976). Oscillations in chemical systems. 13. A detailed molecular mechanism for the BrayLiebhafsky reaction of iodate and hydrogen peroxide. J. Am. Chem. Soc. 98, 4345-4361.

Treindl, L. and Noyes, R.M. (1993). A new explanation of the oscillations in the Bray-Liebhafsky reaction. J. Phys. Chem. 97, 11354-11362. 


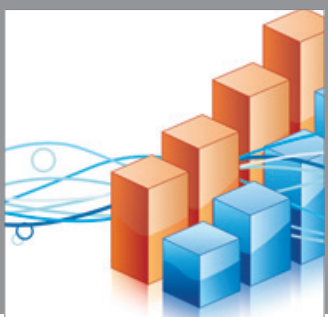

Advances in

Operations Research

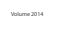

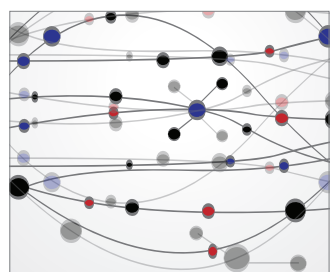

\section{The Scientific} World Journal
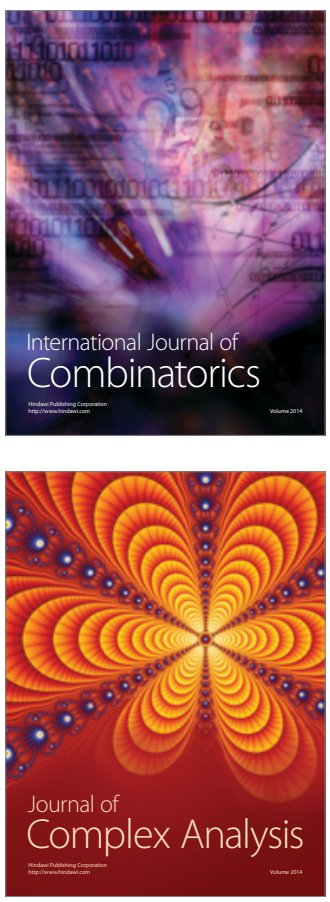

International Journal of

Mathematics and

Mathematical

Sciences
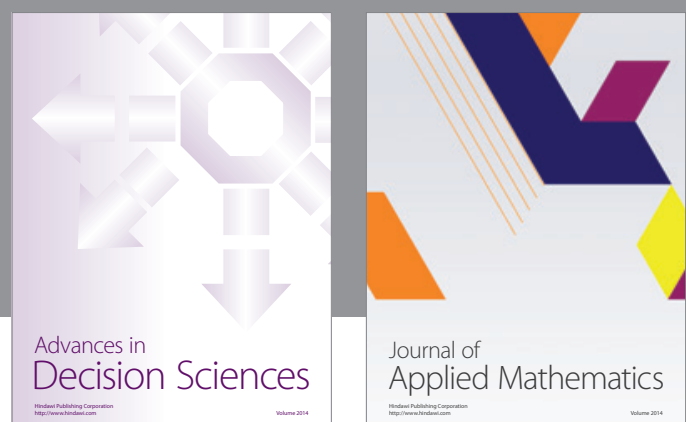

Journal of

Applied Mathematics
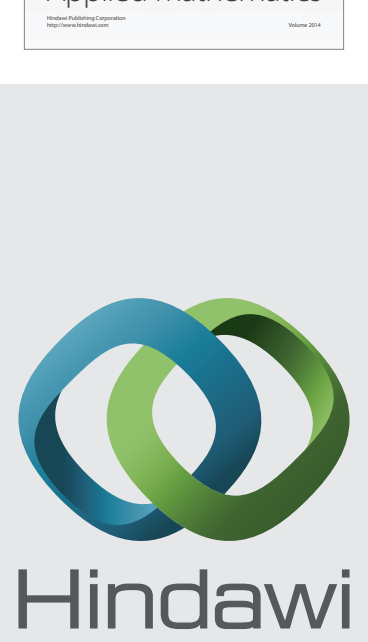

Submit your manuscripts at http://www.hindawi.com
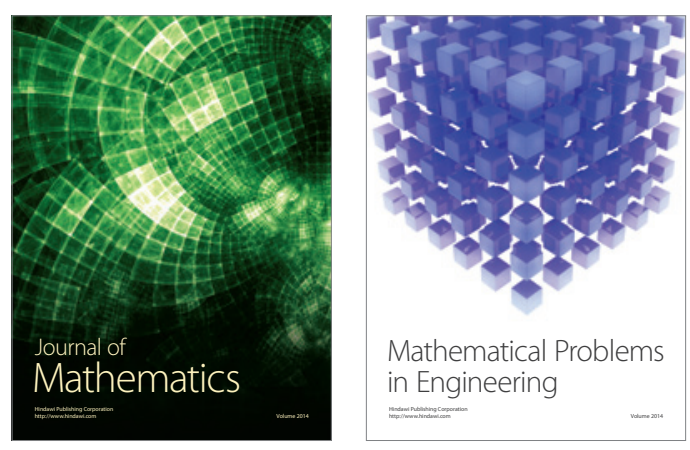

Mathematical Problems in Engineering
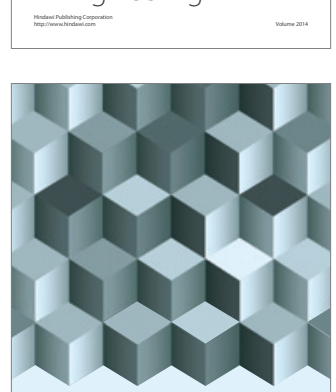

Journal of

Function Spaces
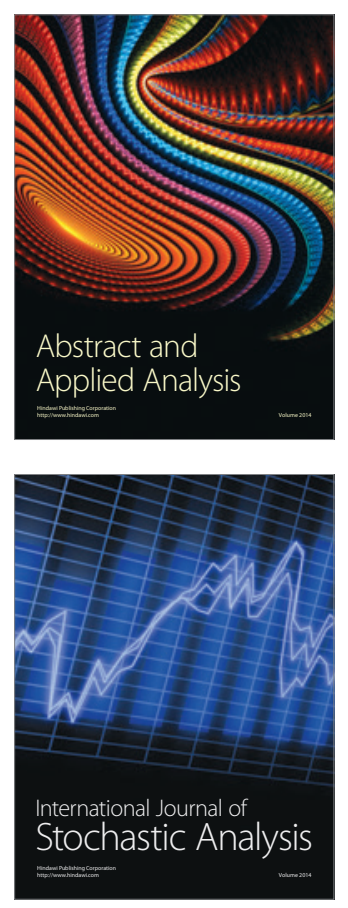

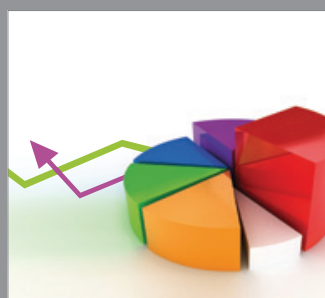

ournal of

Probability and Statistics

Promensencen
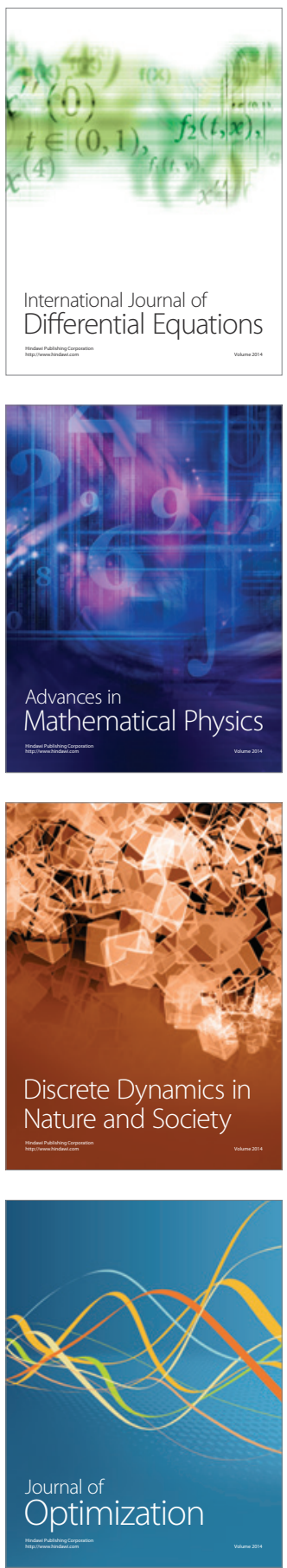